\title{
Temporal dynamics of human-excreted pollutants in wastewater treatment plant influents: toward a better knowledge of mass load fluctuations
}

Thomas Thiebault $^{\mathrm{a}^{*}}$, Laëtitia Fougère ${ }^{\mathrm{b}}$, Emilie Destandau ${ }^{\mathrm{b}}$, Maxime Réty ${ }^{\mathrm{a}, \mathrm{b}}$, Jérémy Jacob $^{\mathrm{a}}$

${ }^{a}$ Univ Orleans, CNRS, BRGM, Institut des Sciences de la Terre d'Orléans (ISTO), UMR 7327, 45071 Orleans, France

${ }^{\mathrm{b}}$ Univ Orleans, CNRS, ICOA, UMR 7311, 45067 Orleans, France

*To whom correspondence should be addressed. E-mail: thomas.thiebault@cnrs-orleans.fr Phone: +33 (0) 2384925 66. Fax: +33 (0) 238636488

Keywords

- Pharmaceuticals

- Illicit Drugs

- Consumption

- Wastewater-based epidemiology

- Temporal dynamics

\section{Abstract}

The occurrence of 25 drug target residues (illicit drugs or pharmaceutically active compounds) was investigated during 85 consecutive days in the influents of a wastewater treatment plant in the Region Centre-Val de Loire, France. This long tracking period allowed a better understanding of the patterns affecting the occurrence of this type of contaminants. Among them, 2 were never detected (i.e. heroin and amphetamine). Concerning illicit drugs two patterns were found. Cocaine and ecstasy median loads varied considerably between weekdays and weekend days (i.e. 18.3 and $35.9 \%$ respectively) whereas cannabis and heroin (based on 6-mono-acetylmorphine loads) loads were within the same order of magnitude with a significant statistical correlation with pharmaceuticals such as acetaminophen or ketoprofen. 
The consumption of selected drugs was back-calculated from the loads. Among illicit drugs the highest consumption was found for cannabis with a median consumption of $51{\mathrm{mg} . d a y^{-}}^{-}$ ${ }^{1}$.inhabitant ${ }^{-1}$ (inh) whereas the median consumption for cocaine (based on benzoylecgonine loads) and ecstasy was 32 and 6 mg.day ${ }^{-1} \cdot 10^{3} \cdot \mathrm{inh}^{-1}$ respectively.

The highest consumption values of pharmaceutically active compounds (PACs) were found for acetaminophen and acetylsalicylic acid with 108.8 and $34.1 \mathrm{mg}$ day ${ }^{-1} \cdot$.inh $^{-1}$ respectively, in good agreement with national sales data. A statistically significant weekly pattern was found for several PACs such as metoprolol and trimethoprim, but with the opposite pattern to that of illicit drugs. The variations in daily PAC loads could provide information about the mobility of people in the catchment, especially on the basis of daily taken PACs (i.e. to treat chronicle diseases).

\section{Introduction}

Emerging pollutants constitute a major, common, and persistent form of pollution in numerous environmental compartments (Bueno et al., 2012; Deblonde et al., 2011). Among them, pharmaceutically active compounds (PACs) present significant concentrations in natural waters, from ng.L $\mathrm{L}^{-1}$ to $\mu \mathrm{g} . \mathrm{L}^{-1}$ (Loos et al., 2009; Lopez et al., 2015; Mompelat et al., 2009). These contaminants originate from human and animal therapies and are excreted at a significant rate via urine and feces, depending on the compound characteristics (Lienert et al., 2007). Similarly, illicit drugs (IDs) are human-excreted contaminants, for which the level of contamination and the route leading to the natural environment are the same as those of PACs (Kasprzyk-Hordern et al., 2008; Postigo et al., 2010). After excretion, these compounds are mainly transferred to wastewater treatment plants (WTPs) where their incomplete removal constitutes a potential hazard for numerous living organisms, including humans (Brodin et al., 2014; de Jongh et al., 2012). 
Most studies on PACs and IDs concern the assessment of their removal in classical WTPs (e.g. Fatta-Kassinos et al., 2011; Petrovic et al., 2009; Subedi and Kannan, 2014; Verlicchi et al., 2012) or focus on innovative techniques aiming at optimizing removal in order to protect natural environments (e.g. Rattier et al., 2014; Thiebault et al., 2016).

Yet, it appears crucial to better understand the temporal dynamics of PACs and IDs in order to both adjust the removal capacity of WTPs and predict contamination levels in natural waters.

Consumption of PACs is known to vary with time mainly due to the medication rate of each therapeutic class. For example, antibiotics are occasional medications strongly impacted by seasonality (Golovko et al., 2014). Conversely, $\beta$-blockers and anti-diabetics are consumed on a more regular basis, because they treat chronic diseases (Sui et al., 2011). It can therefore be assumed that PAC concentrations exhibit different temporal dynamics depending on their therapeutic targets. The temporal dynamics of IDs are less understood although a relationship has been established between an increase in loads of certain IDs (i.e. recreational drugs) following several patterns such as special events (Gerrity et al., 2011) and weekends (Gatidou et al., 2016; van Nuijs et al., 2011). According to recent studies, the level of contamination of a wide range of PACs and IDs in the influent of WTPs can be correlated to the consumption rate of the population (Baker et al., 2014; Baz-Lomba et al., 2016; Celle-Jeanton et al., 2014; Krizman et al., 2016), to the amount of inhabitants in the catchment (Lai et al., 2016) and to the level of contamination within natural environments (Klaminder et al., 2015). The calculation of consumption based on loads of drug target residue (DTR) in wastewater treatment plant influents (influents) requires the use of several parameters: (i) the concentrations of DTR in influents, (ii) the flow rate of influents, (iii) the number of inhabitants in the catchment of the WTP and (iv) the percentage of parent compound excreted as DTR, the molar ratio, the stability and the sorption 
onto suspended particles, data that are available in the literature, albeit with some variations (Gracia-Lor et al., 2016).

Numerous studies directly compare the loads of DTR in influents with consumption levels (Besse et al., 2008; Chiffre et al., 2016; Yan et al., 2014). Few consider that the transit from excretion to arrival at the WTP can affect the form and the amount of both PACs and IDs, depending on their chemical reactivity, their sensitivity to degradation and to the physico-chemical conditions that prevail in the medium during transport. Changes in the physico-chemical conditions could therefore constitute an additional parameter that should be taken into account to explain the temporal variability of DTR loads in influents. A large dataset is also helpful to assess the temporal variability of contaminant loads in influents as it could highlight certain temporal patterns in DTR loads, making it possible to assess their regularity over time. In this study, we present for the first time the daily evolution of PACs and IDs based on 25 DTR loads during 85 consecutive days. The large dataset enabled us to (i) determine the temporal trends of various PACs and IDs on a season scale; (ii) compare the results with predicted loads and consumption in order to detect some site-specific features; (iii) use the statistical correlations between DTR in order to better understand parameters that impacting their excretion/consumption.

\section{Material and methods}

\subsection{Sample collection and general setting}

Influents were collected each day during 85 consecutive days, between March $21^{\text {st }}$ and June $13^{\text {th }}$ 2016 except on March $31^{\text {st }}$, providing a set of 84 samples. Sampling consisted of a volumeproportional composite with a sampling of $50 \mathrm{~mL}$ every $30 \mathrm{~m}^{3}$ of influents between $0 \mathrm{~h} 00$ and 23h59. For the mean influent volume value, this corresponds to a mix of 167 samples per day. The chemical parameters of influents during the study are given in Table S1. The selected WTP 
has a capacity of 94,000 population-equivalents corrected to 70,000 inhabitants (inh) considering the number of inhabitants on the catchment. Because IDs are not innocuous pollutants from a political and epidemiological point of view, the exact emplacement of the WTP investigated in this study is not disclosed, in accordance with ethical guidelines (Hall et al., 2012; Prichard et al., 2014)

\subsection{Chemical Reagents}

Standards for acetaminophen (ACM), atenolol (ATE), bezafibrate (BZB), carbamazepine (CBZ), codeine (COD), diclofenac (DCF), ibuprofen (IBP), ketoprofen (KET), metoprolol (MET), oxazepam (OXA), salicylic acid (SCA), sulfamethoxazole (SUL), tramadol (TRA) and trimethoprim (TMP) were purchased from Sigma-Aldrich with a purity $>98 \%$. The standards for 6-mono-acetylmorphine (6MAM), amphetamine (AMP), benzoylecgonine (BZE), buprenorphine (BUP), cocathylene (CET), cocaine (COC), heroin (HER), 3,4-methylene-dioxy-Nmethylamphetamine (MDMA), methadone (METD), morphine (MOR) and 11-nor-delta-9hydroxytetrahydrocannabinol (THC-COOH) were purchased from LGC Standards. Extraction and separation solvents, methanol $(\mathrm{MeOH})$ and acetonitrile $(\mathrm{AcN})$ were purchased from FisherScientific, assuming an analytical grade (purity up to $99.95 \%$ ).

\subsection{Sample Preparation}

After collection, influents were filtered with glass-fiber filters (GF/F, Whatman) prior to solidphase extraction (SPE). SPE was carried out by using Chromabond HR-X cartridges ( $6 \mathrm{~mL}$ x 500 $\mathrm{mg}$, Macherey-Nagel). Cartridges were conditioned with $6 \mathrm{~mL}$ of $\mathrm{MeOH}$ followed by $6 \mathrm{~mL}$ of ultra-pure water. Then, the cartridges were filled with $250 \mathrm{~mL}$ of influent prior to flushing with 6 $\mathrm{mL}$ of ultra-pure water before drying for 30 minutes under vacuum. Finally, elution of DTR was 
performed with $6 \mathrm{~mL}$ of $\mathrm{MeOH}$ before drying under nitrogen flow and storage at $-10^{\circ} \mathrm{C}$. Samples were recovered in ultra-pure water acidified with $0.1 \%$ of formic acid before injection.

\subsection{Quantification and validation}

Chromatographic separation was achieved with an Ultimate 3000 RSLC (Thermo Fisher Scientific Inc., CA, USA) liquid chromatography system equipped with a binary pump and a Nucleodur $\mathrm{C}_{18}$ Gravity column (150mm x $3 \mu \mathrm{m}$, Macherey-Nagel) supplemented by a guard column. Separation was performed at a flow rate of $1 \mathrm{~mL} \cdot \mathrm{min}^{-1}$ and the temperature was maintained at $30^{\circ} \mathrm{C}$. Two solvents were used as mobile phase: ultrapure water (solvent A) and AcN (solvent B) both acidified with $0.1 \%$ of formic acid. The elution gradient was a transition from $95 \%$ to $5 \%$ of $\mathrm{A}$ in $50 \mathrm{~min}$ followed by $10 \mathrm{~min}$ of $100 \%$ of $\mathrm{B}$ and then a return to the initial conditions (95\% of A) during $10 \mathrm{~min}$ for a total analysis time of $71 \mathrm{~min}$. The chromatography system was coupled to a TSQ Endura triple quadrupole mass spectrometer equipped with a heated electrospray ionization (H-ESI) interface (Thermo Scientific Inc., San Jose, CA, USA) and at a flow rate of $0.3 \mathrm{~mL} \cdot \mathrm{min}^{-1}$. Quantification was performed with an electrospray ionization source operating in positive mode, with an electrospray voltage of $3600 \mathrm{~V}$, a vaporizer temperature of $425^{\circ} \mathrm{C}$, ion transfer temperature of $325^{\circ} \mathrm{C}$, sheath gas of $50 \mathrm{Arb}$, auxiliary gas of $20 \mathrm{Arb}$, and sweep gas of 1 Arb. Quantification performances are given in Table 1. Further information on the analytical setup can be found in Table S2.

The sample analysis was systematically validated by the following procedure: a calibration curve in ultra-pure water (concentrations varied with linearity range, see Table S1 for details), three sets of 5 samples followed by one control ( 50 or $5 \mu \mathrm{g} . \mathrm{L}^{-1}$ spiked in ultra-pure water) and one blank (ultra-pure water), and another calibration curve. With this procedure, the potential drift of the 
analysis between each calibration curve was assessed. Method Detection Limit (MDL) and Method Quantification Limit (MQL) were calculated with a signal-to-noise ratio of 3 and 10, respectively (Jelic et al., 2011). It should also be noted that the linearity, determined by the linear correlation coefficient $\mathrm{R}^{2}$, takes into account three calibration curves that framed the sample analysis.

The three analytical runs (30 samples for each) were conducted at different times. The betweenrun drift was also determined, by comparing the calibration curves and analyzing the same sample in two different runs.

Relative standard deviation was determined by analyzing the same sample three times. The Recovery Ratios were calculated for each compound by comparing the concentration of a standard spiked in the influent matrix with and without filtration and SPE (at 0.2 and $50 \mu \mathrm{g} . \mathrm{L}^{-1}$ respectively) in triplicate experiments. Matrix effect was assessed for each compound by comparing the concentration of standards spiked in ultra-pure water and spiked in the influent matrix at the same concentration (i.e. $50 \mu \mathrm{g} . \mathrm{L}^{-1}$ ) in triplicate experiment. All further details are given in Table 1.

\subsection{Results treatment}

The concentration values were corrected for several analytical factors (i.e. recovery ratio and matrix effect) in order to further obtain consistent values in units that (i) can be compared to the literature focusing on the loads of DTRs in influents and (ii) can be discussed in terms of temporal dynamics of loads. Firstly, concentrations were converted into loads in order to take into account the irregularity of the flow. Some extreme flow values (Table S1) are indeed generated by the contamination of influents by rainwater, 
despite the separated sewer system (Figure S2). The load of each DTR that arrived at the WTP each day was calculated as follows:

$$
\text { load }=10^{3} \times C \times F
$$

with the load of DTR in g.day ${ }^{-1}, C$, the concentration in $\mu \mathrm{g} . \mathrm{L}^{-1}$, and $F$, the flow in $\mathrm{m}^{3}$.day ${ }^{-1}$ The next calculation transformed the loads into Population-Normalized Loads (PNL) in order to assess the excretion rate of an average median citizen.

$$
\mathrm{PNL}=\frac{\operatorname{load} x 10^{6}}{n_{P E}}
$$

with PNL in $\mu$ g.day ${ }^{-1}$ inh $^{-1}$ and $n_{P E}$, the number of inhabitants around the WWTP.

All these calculations only take into account DTR in the dissolved phase. To calculate the daily Consumption of each DTR, a Correction Factor was applied by taking into account their sorption properties onto suspended particles, their excretion rate and the molar ratio between the parent compound and the DTR, based on literature data (e.g. Gracia-Lor et al., 2016).

$$
\begin{gathered}
\text { Correction Factor }=\frac{\text { Molar Ratio }}{E x R} \times \frac{100}{(100-S S P)} \times \frac{100}{(100+\text { Stability })} \\
\text { Consumption }=\text { Correction Factor } \times \text { PNL }
\end{gathered}
$$

with Consumption, the estimated consumption in $\mu$ g.day ${ }^{-1} \cdot \mathrm{inh}^{-1}, E x R$, the excretion rate as parent compound in \%, Molar Ratio, the ratio between the molecular weight of the parent compound and the molecular weight of the targeted residue both in $\mathrm{g} \cdot \mathrm{mol}^{-1}, S S P$ the sorption onto suspended particles in $\%$ and Stability the stability of the DTR in similar conditions $\left(\mathrm{pH} \approx 7.4\right.$ and $\left.\mathrm{T} \approx 18^{\circ} \mathrm{C}\right)$.

The assessment of weekday and weekend loads was carried out by using loads of Saturday, Sunday and Monday (SAT-MON) for the weekend and the remaining days for 
the week (TUE-FRI). This choice was motivated by the connection between rainfall and the flow of influents (Figure S2), showing that the residence time of influents in sewers is between 0 and 1 day, and also by several studies using the same distinction (Baker et al., 2014; van Nuijs et al., 2011; Vuori et al., 2014).

Correlation matrix and pairwise $p$-values were performed by using the package FactoMineR of the R software (Lê et al., 2008). Statistical analyses were performed on load values. The Pearson correlation was used to assess both the correlation matrix and $p$-values.

\begin{tabular}{|c|c|c|c|c|c|c|c|c|c|}
\hline \multirow[b]{2}{*}{ Abbreviation } & \multirow{2}{*}{\multicolumn{2}{|c|}{ DTR }} & \multirow{2}{*}{$\begin{array}{l}\text { Matrix Effect } \\
\pm \mathrm{SD}(\%)\end{array}$} & \multirow{2}{*}{$\begin{array}{c}\text { Recovery Ratio } \\
\pm \% \operatorname{SD}(\%)\end{array}$} & \multirow{2}{*}{$\begin{array}{l}\mathrm{MDL} \\
\mathrm{ng} \cdot \mathrm{L}^{-1}\end{array}$} & \multirow{2}{*}{$\begin{array}{l}\mathrm{MQL} \\
\mathrm{ng} \cdot \mathrm{L}^{-1}\end{array}$} & \multirow{2}{*}{ Linearity } & \multicolumn{2}{|c|}{ Instrument Performance } \\
\hline & & & & & & & & $\begin{array}{c}\text { Intra-day } \\
(\%)\end{array}$ & $\begin{array}{c}\text { Inter-day } \\
(\%)\end{array}$ \\
\hline \multicolumn{10}{|l|}{ Antibiotics } \\
\hline SUL & & Sulfamethoxazole & $91 \pm 1.58$ & $79.7 \pm 9.00$ & 0.2 & 0.5 & 0.9998 & 2.1 & 2.6 \\
\hline$T M P$ & & Trimethoprim & $109 \pm 0.43$ & $71.4 \pm 3.81$ & 0.1 & 0.4 & 0.9999 & 2.8 & 1.5 \\
\hline \multicolumn{10}{|c|}{ Anti-inflammatory drugs + Analgesics } \\
\hline$I B P$ & & Ibuprofen & $108 \pm 4.28$ & $78.9 \pm 3.63$ & 0.9 & 2.8 & 0.9972 & 6.8 & 3.2 \\
\hline$D C F$ & & Diclofenac & $188 \pm 0.40$ & $62.9 \pm 2.00$ & 0.3 & 0.8 & 0.9994 & 2.4 & 6.1 \\
\hline KET & & Ketoprofen & $123 \pm 1.73$ & $67.4 \pm 5.36$ & 0.6 & 1.9 & 0.9998 & 4.6 & 0.9 \\
\hline$S C A$ & & Salicylic Acid & $188 \pm 0.70$ & $22.1 \pm 9.24$ & 0.4 & 1.3 & 0.9997 & 2.1 & 1.1 \\
\hline$A C M$ & & Acetaminophen & $349 \pm 0.29$ & $99.6 \pm 9.99$ & 0.6 & 1.7 & 0.9998 & 4.6 & 3.1 \\
\hline \multicolumn{10}{|l|}{ Other PACs } \\
\hline$A T E$ & & Atenolol & $117 \pm 1.38$ & $68.3 \pm 3.56$ & 0.3 & 0.8 & 0.9998 & 2.8 & 1.8 \\
\hline$M E T$ & & Metoprolol & $113 \pm 1.67$ & $79.4 \pm 2.62$ & 0.1 & 0.2 & 0.9998 & 2.4 & 1.4 \\
\hline$O X A$ & & Oxazepam & $168 \pm 1.42$ & $103.5 \pm 1.15$ & 2.3 & 6.4 & 0.9994 & 2.0 & 1.5 \\
\hline$C B Z$ & & Carbamazepine & $142 \pm 0.48$ & $101.1 \pm 4.75$ & 1.6 & 4.6 & 0.9975 & 1.0 & 3.2 \\
\hline$B Z B$ & & Bezafibrate & $112 \pm 2.79$ & $80.5 \pm 6.09$ & 0.5 & 1.3 & 0.9998 & 3.1 & 2.9 \\
\hline \multicolumn{10}{|c|}{ Opioids and derivatives } \\
\hline$M O R$ & & Morphine & $108 \pm 1.05$ & $52.3 \pm 5.14$ & 3.1 & 8.9 & 0.9996 & 6.1 & 2.0 \\
\hline 6MAM & & 6-mono-acetylmorphine & $171 \pm 3.78$ & $59.7 \pm 4.72$ & 1.0 & 2.8 & 0.9996 & 1.6 & 4.0 \\
\hline$H E R$ & & Heroin & $112 \pm 2.56$ & $68.9 \pm 6.72$ & 6.4 & 17.3 & 0.9937 & 9.7 & 3.1 \\
\hline METD & & Methadone & $235 \pm 0.69$ & $65.8 \pm 13.6$ & 2.2 & 7.8 & 0.9985 & 3.8 & 1.6 \\
\hline$C O D$ & & Codeine & $111 \pm 0.59$ & $58.1 \pm 2.88$ & 0.5 & 1.4 & 0.9998 & 6.8 & 2.3 \\
\hline$B U P$ & & Buprenorphine & $241 \pm 2.50$ & $53.9 \pm 12.4$ & 0.8 & 2.6 & 0.9988 & 10.1 & 7.2 \\
\hline$T R A$ & & Tramadol & $171 \pm 1.54$ & $99.0 \pm 2.46$ & 2.1 & 6.5 & 0.9997 & 3.9 & 6.4 \\
\hline
\end{tabular}


Cocaine and derivatives

$\begin{array}{lcccccccc}\text { COC } & \text { Cocaine } & 80 \pm 2.23 & 78.0 \pm 5.47 & 1.6 & 4.9 & 0.9989 & 8.9 & 2.7 \\ \text { BZE } & \text { Benzoylecgonine } & 109 \pm 1.36 & 82.8 \pm 3.15 & 1.8 & 5.4 & 0.9996 & 4.3 & 1.9 \\ \text { CET } & \text { Cocaethylene } & 096 \pm 1.54 & 83.6 \pm 3.59 & 0.6 & 2.0 & 0.9996 & 6.6 & 2.6\end{array}$

Other IDs

THC

MDMA

AMP
THC-COOH

MDMA

Amphetamine
$124 \pm 2.51$

$108 \pm 0.47$

$105 \pm 0.14$
$43.6 \pm 16.6$

$72.0 \pm 11.5$

$73.5 \pm 9.42$

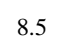

1.6

$\begin{array}{llll}20.2 & 0.9987 & 3.4 & 4.2 \\ 3.2 & 0.9996 & 5.6 & 3.8 \\ 4.6 & 0.9975 & 5.8 & 3.9\end{array}$

Table 1: Analytical parameters and performance of the selected contaminants with SD the standard deviation, MDL and MQL method detection limit and method quantification limit respectively

\section{Results}

\subsection{Loads of DTRs in influents}

Figure 1 presents the aggregation of the 84 load values during the whole period of analysis. HER (as DTR) and AMP are not shown in Figure 1 nor in the rest of the study because they were never detected. As explained above, concentration is not the most consistent value to assess the temporal trend of contaminants. Yet, this value is heavily dependent on the flow. Although there were some significant variations in the concentrations during tracking, the calculation of loads smoothes the impact of extreme events such as the heavy rain events that occurred during the beginning of June 2016 (Figure S1).

The variation for a given DTR never exceeded one order of magnitude during the tracking period, with the notable exception of four compounds (CET, MDMA, 6MAM and BZE) that are all IDs (Figure 1). 


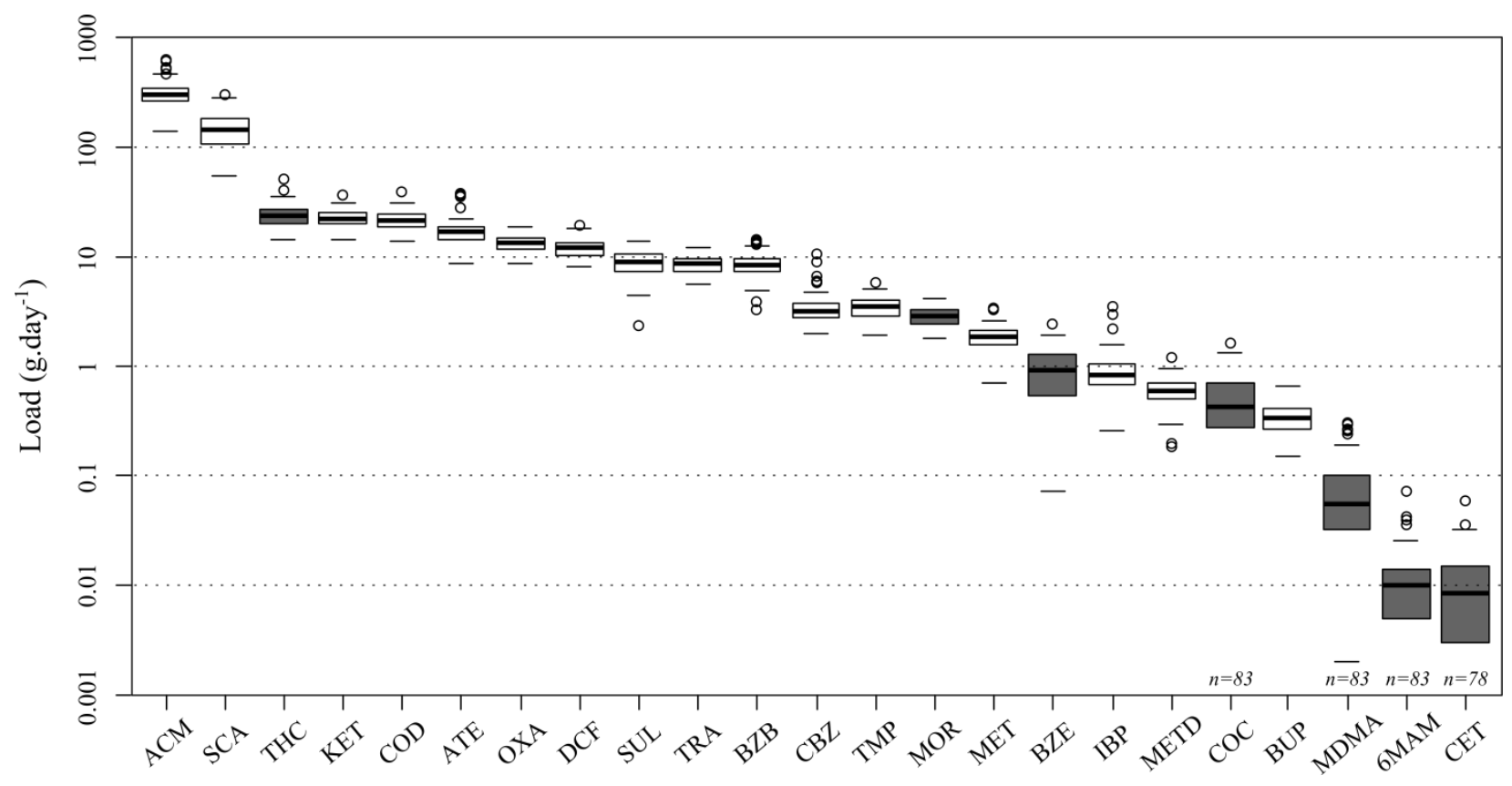

Figure 1: Loads of each DTR during the whole sampling campaign $(n=84)$. The number of detections is indicated if different from 84 . The line within the box marks the median, boundaries indicate the $25^{\text {th }}$ and the $75^{\text {th }}$ percentiles, error bars indicate the maximum and minimal mass loads in $\pm 1.5 \sigma$ variations and dots indicate values outside this range. Gray and white boxes correspond to ID and PAC loads respectively

Among the selected DTRs, ACM and SCA were the two most abundant with median loads of 297.9 and 140.8 g.day $^{-1}$ respectively. The loads of other PACs were between those of BUP and KET values with 0.3 and $22.1 \mathrm{~g} \mathrm{day}^{-1}$ respectively. Finally, among IDs, the loads were in general lower than those of PACs except for THC-COOH with a median load of $23.5 \mathrm{~g} \mathrm{day}^{-1}$.

\subsection{Weekly trends of DTRs}

To assess the factors that control the dynamics of DTRs in influents, the difference between weekday and weekend day loads is an efficient indicator often used for IDs and derivatives (Gatidou et al., 2016; van Nuijs et al., 2011; Vuori et al., 2014; Zuccato et al., 2008).

Figure 2 presents the distribution of DTR loads during weekdays and weekend days. When statistically significant $(p<0.05)$, the percentage difference is indicated above the DTR concerned. Among the 23 DTRs detected, 11 presented a statistically significant difference 
between weekdays and weekend days. 4 of these were IDs for which the loads were higher on weekend days than on weekdays, with median variations of 50.9, 35.9, 20.4 and $18.3 \%$ for CET, MDMA, COC and BZE, respectively. The other 7 are PACs and, except for DCF, their loads were significantly lower on weekend days than on weekdays, with negative percentage values (Figure 2).

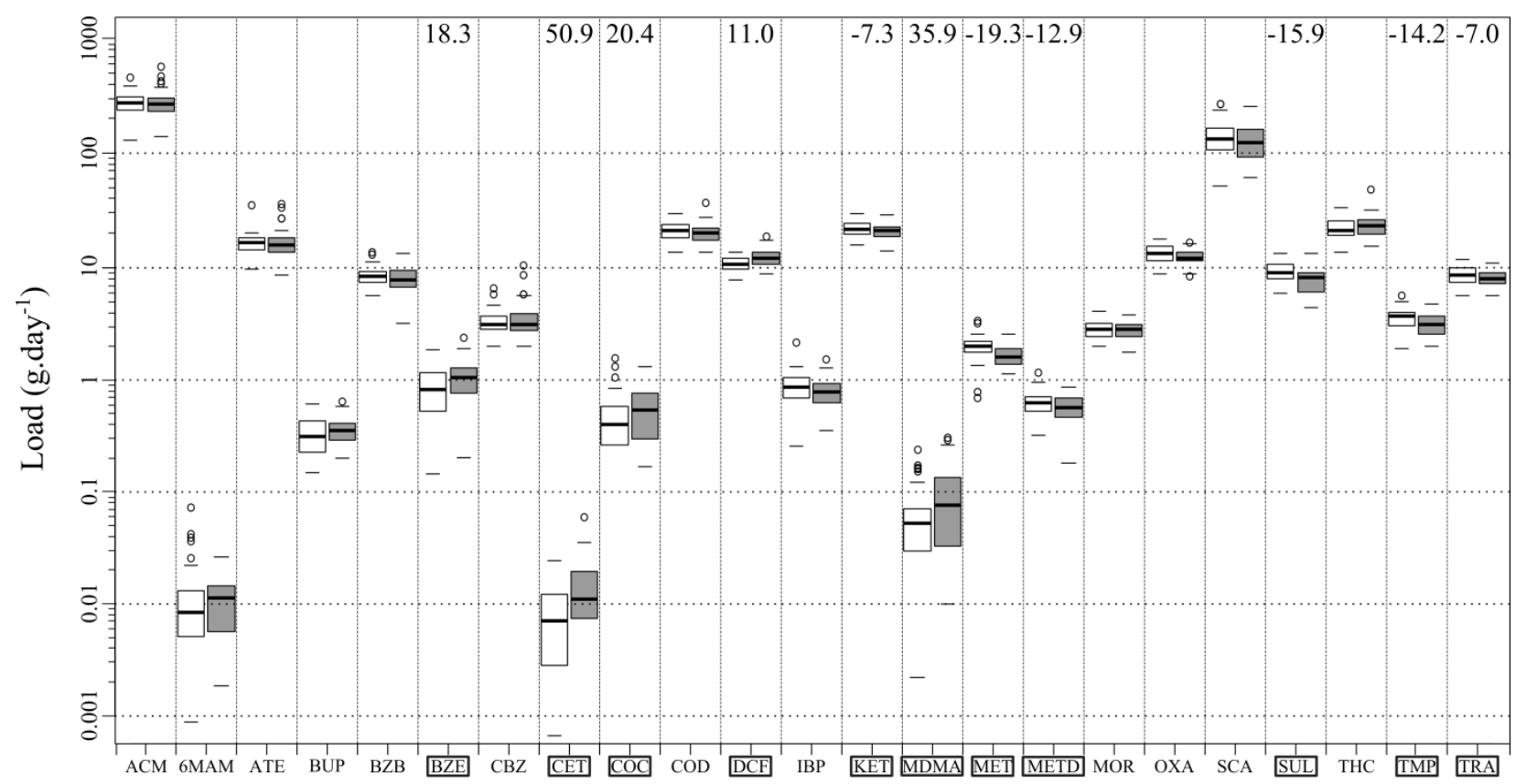

Figure 2: Comparison of loads between week days (white boxes) and weekend days (gray boxes) for each targeted DTR. Numbers at the top of the figure indicate the percentage variation between TUE-FRIand SAT-MON when statistically significant $(p<0.05)$. The line within the box marks the median, boundaries indicate the $25^{\text {th }}$ and the $75^{\text {th }}$ percentiles, error bars indicate the maximum and minimal loads in $\pm 1.5 \sigma$ variations and dots indicate values outside this range

\section{Discussion}

\subsection{Comparison of PNL with literature data}

PNL values of both IDs and PACs are then confronted to data reported in the literature. The median PNL values obtained in this study for PACs are in accordance with literature data (Figure 3). Thus, the excretion of an average citizen in the catchment of the selected WTP is comparable to that of others worldwide. For example, the PNL values for SUL and MET are very similar to 
median PNL values reported in literature data (Figure 3). However, some values are significantly different from those found in the literature. For example, the median PNL of KET determined in the present study is the highest of those reported in the literature whereas the median PNL of IBP is the lowest (Figure 3). PNL values of IDs are also different from literature data. For example, although BZE, COC, MDMA, 6MAM and CET were frequently detected in this study, their PNL values are lower than those reported in earlier studies. This can be explained by several factors. Firstly, the investigated area is not as densely populated as major cities examined in the literature. It has been shown that ID excretion is higher in major cities (Ort et al., 2014; Thomas et al., 2012; Vuori et al., 2014). Moreover, the selected WTP mostly drains residential and industrial areas but few party locations. Finally, the PNL values reported in Figure 3 are only those higher than the MQL (i.e. > 0 in the literature). Yet, a significant proportion of the cited studies did not detect compounds such as MDMA or 6MAM, for example. The PNL values determined in this study are lower than other reports but remain significantly higher than MQL.

In this study, the median PNL value for THC-COOH is $261 \mu$ g.day.inh ${ }^{-1}$ whereas the previous highest value reported was $259 \mu$ g.day.inh ${ }^{-1}$ in Paris (Thomas et al., 2012). 


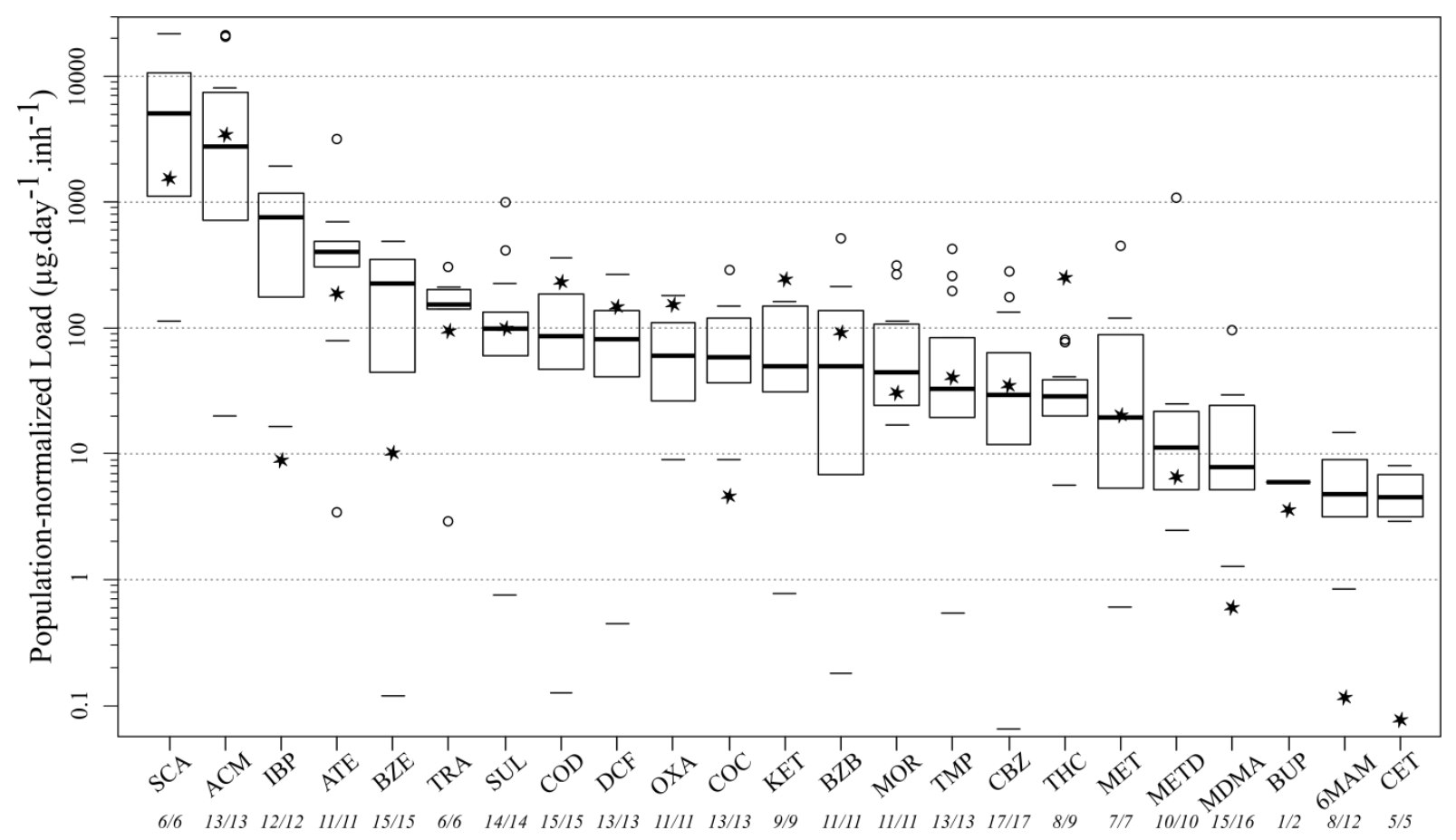

Figure 3: Median PNL of each DTR obtained in this study (black stars) compared with literature data (box-plot). The number indicated below each abbreviation indicates the number of values > MQL/total number of values in the literature. The line within the box marks the median, boundaries indicate the $25^{\text {th }}$ and the $75^{\text {th }}$ percentiles, error bars indicate the maximum and minimal mass loads in $\pm 1.5 \sigma$ variations and dots indicate values outside this range

Data from: Baker et al. (2014); Behera et al. (2011); Bijlsma et al. (2012); Castiglioni et al. (2006a, 2006b); Collado et al. (2014); Gerrity et al. (2011); Golovko et al. (2014); Gracia-Lor et al. (2012); Gurke et al. (2015); Kosma et al. (2014); Lindberg et al. (2014); Mackul'ak et al. (2016); Mailler et al. (2015); Ort et al. (2014); Papageorgiou et al. (2016); Pereira et al. (2016); Postigo et al. (2011, 2010); Rosal et al. (2010); Terzic et al. (2010); Vergeynst et al. (2015); Verlicchi et al. (2013); Vuori et al. (2014); Wick et al. (2009); Yan et al. (2014)

\subsection{Consumption assessment and its temporal dynamics}

A wastewater-based consumption can be calculated from the load values. We converted loads into consumption in order to compare our data with predicted consumption at the national scale, based on sales figures. While the predicted consumption of PACs is available (Chiffre et al., 2016), this is, obviously, not the case for IDs. Moreover, the defined daily dose (DDD) has been calculated for several PACs, making it possible to calculate the number of consumers based on the load value (Baz-Lomba et al., 2016). For IDs, it is only possible to calculate the number of doses.1000inh ${ }^{-1}$. The presentation of the results will therefore be different for PACs and IDs. 
PAC consumption will be compared to predicted values and based on DDD values (Table 2) while ID consumption will be determined from the number of doses (Table 3).

\section{Antibiotics}

The wastewater-based consumption values of both SUL and TMP are very close to those predicted at the national scale (Table 2). The case of SUL and TMP is particular, however, as these two antibiotics are often associated in a single medicinal product, with a SUL/TMP ratio of 5/1 (Dan et al., 2013). In our data, the statistical correlation between SUL and TMP loads is the highest with a value of $0.65(p<0.001)$, thus confirming the relationship between these two PACs (Table 4).

Yet, the calculated SUL/TMP ratio is $7.5 / 1$, a value close to the original ratio, but nonetheless distinct. It can therefore be considered that TMP is less stable during the transfer through the sewer network, increasing the SUL/TMP ratio in the influent. The same could apply for other PACs consumed in association. However SUL and TMP are the two only PACs for which the associated medication is predominantly consumed than single PAC (e.g. ACM/TRA or $\mathrm{ACM} / \mathrm{COD})$.

Due to the significant correlation between SUL and TMP, the temporal trends of their loads are also significantly correlated, and exhibit lower loads during weekend days and higher loads during weekdays in the same order of magnitude for both (i.e. -15.9 and $-14.2 \%$ for SUL and TMP respectively, Figure 2).

However, their variable posology (antibiotics are by definition an episodic medication) especially sensible to monthly or hourly rather than daily variations (Coutu et al., 2013), and dosage (i.e. from 200 to $800 \mathrm{mg}$ of SUL, 40 to $160 \mathrm{mg}$ of TMP, 1 to 3 three times per day, Plósz et al., 2010), makes it difficult to ascertain the origin of this weekday/weekend difference. Anti-inflammatory drugs and Analgesics 
Within this therapeutic group, ACM and SCA were the two most abundant DTR detected in this study. The wastewater-based consumption values for these two PACs exceeded $10 \mathrm{mg} \cdot \mathrm{day}^{-1} \cdot \mathrm{inh}^{-1}$, in good accordance with predicted values (Table 2). The posology of acetylsalicylic acid (of which SCA is the DTR) and ACM are episodic, as for the other PACs present in this group. We therefore expect significant day-to-day variations in the influent loads of these DTRs. Yet, the loads of these PACs are regular (i.e. in the same order of magnitude) all along the tracking indicating that the wastewater-based consumption weakly varied during this tracking (Figure 1 and S1).

Baz-Lomba et al. (2016) used a DDD of 3 grams to assess the consumer number of ACM. Based on a mean PNL of 4,353 $\mu$ g.day ${ }^{-1} \cdot \mathrm{inh}^{-1}$, this corresponds to a median amount of 2539 DDD or daily consumers of ACM based on the median consumption value (Table 2). It can therefore be estimated that the median percentage of ACM consumers in the catchment is $3.6 \%$ (i.e. 2539 ACM consumers.70000inh ${ }^{-1}$ ).

Among this therapeutic class, only DCF presents a significant difference in load values between weekend days and weekdays. However due to its posology, it is difficult to draw any further conclusion.

Significant statistical correlations between all the compounds in this group indicate that a common factor could control their consumption (Table 4).

The calculated consumptions are in general agreement with theoretical consumption values, with the noticeable exception of IBP for which the wastewater-based consumption is $0.4 \%$ of the predicted one (Table 2). This significant difference, already noticed when compared the PNL value with other WTPs (Figure 3), could be explained by a site effect. A previous study carried out in the same region also gave low consumption values for IBP (Thiebault et al., 2017).

Other PACs 
ATE and MET are $\beta$-blockers and can be considered as all-year-long medication. Their wastewater-based consumption values are within the same order of magnitude as national sales values (Table 2). Thanks to the particular posology of ATE and MET, the number of daily consumers around the WTP can be calculated. With DDD of 70 and $150 \mathrm{mg}$, respectively (BazLomba et al., 2016), the number of DDDs excreted for ATE and MET in the catchment are on average 4.59 and 1.62 DDD.day ${ }^{-1} .1000 \mathrm{inh}^{-1}$, respectively. Although the loads of ATE did not exhibit any trend, a weekly pattern can be distinguished for MET (Figure 2), since MET is significantly less excreted in the catchment during the weekend. The mean DDD amounts are therefore 1.74 and 1.46 DDD.day ${ }^{-1} .1000 \mathrm{inh}^{-1}$ on weekdays and weekend days, respectively. This variation can be observed throughout the record. It may be interpreted as the possible mobility of a fraction of MET consumers, for example workers who work in the catchment but live outside of it.

CBZ and BZB wastewater-based consumptions are close to theoretical values based on national sales data (Table 2) and no temporal pattern can be distinguished (Figure 2).

The estimated consumption of OXA is very close to the theoretical one. OXA is not only consumed as PAC (Hummel et al., 2006), but it is also a DTR of diazepam (Baker et al., 2014). The wastewater-based consumption of diazepam based on OXA loads is thirty times higher than predicted consumption based on national sales. This is due to the fact that in France, OXA is consumed ten times more than diazepam (Table 2). The assumption that OXA can be a good indicator of benzodiazepines in general seems correct. Conversely, estimating diazepam consumption from OXA loads appears inappropriate (Bijlsma et al., 2012). 


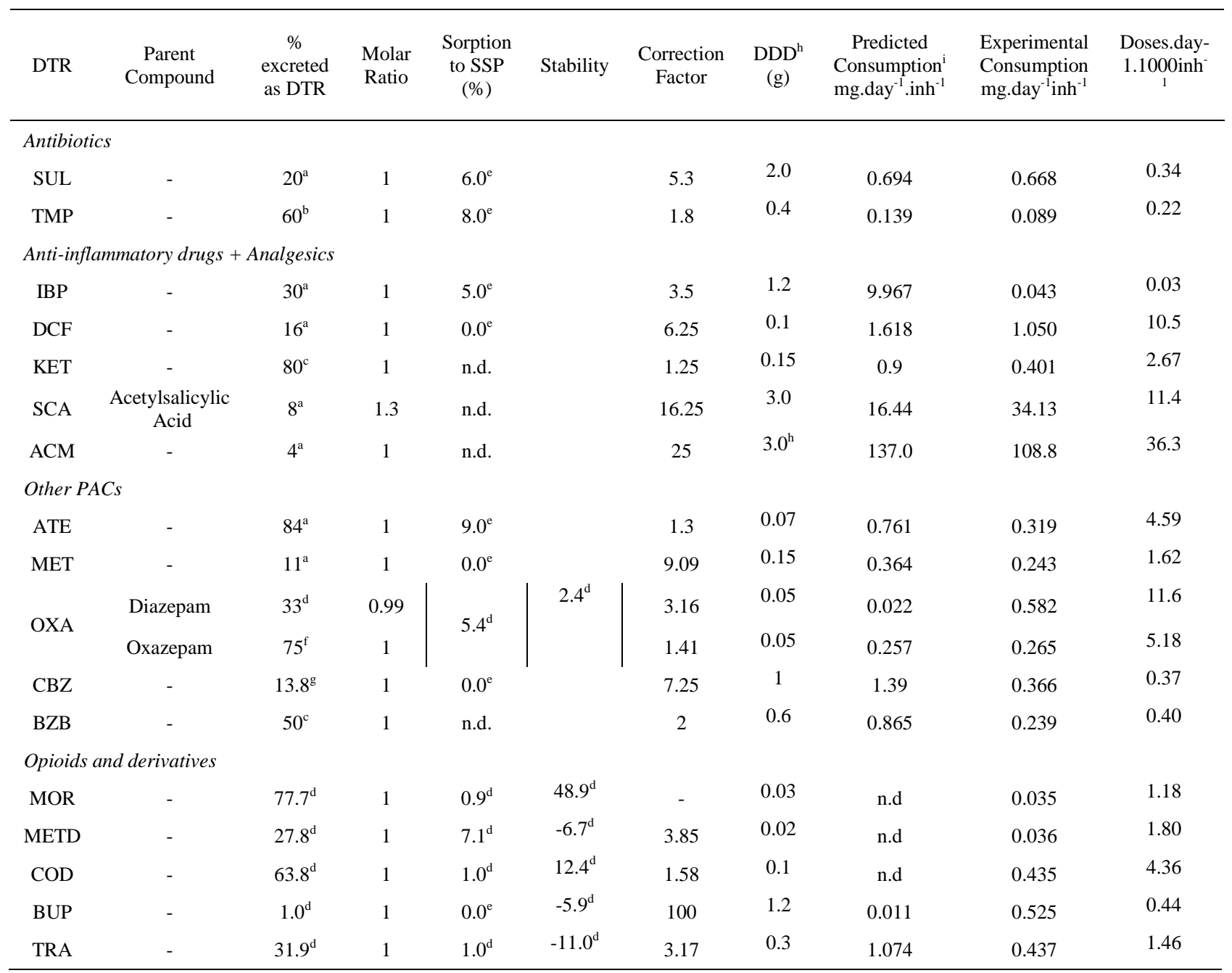

Table 2: Assessment of the median wastewater-based consumption and a comparison with theoretical consumption values based on national sales data, with SSP the suspended solid particles

References:

Lienert et al. (2007) $)^{\mathrm{a}}$

Hirsch et al. (1999) ${ }^{\mathrm{b}}$

Kasprzyk-Hordern et al. (2009) ${ }^{\mathrm{c}}$

Baker et al. (2014) ${ }^{\mathrm{d}}$

Hörsing et al. (2011)

Carballa et al. $(2008)^{\mathrm{f}}$

Bahlmann et al. (2014) $)^{\mathrm{g}}$

WHO Collaborating Center for Drug Statistics Methodology $(2016)^{\mathrm{h}}$

Chiffre et al. (2016)

Opioids and derivatives

National sales data are only available for two DTR of opioids: BUP and TRA. The wastewaterbased consumption of TRA is in the same order of magnitude as national sales data, whereas for 
BUP, the wastewater-based consumption is significantly higher (Table 2). METD and COD are two other PACs consumed in significant amounts. The measured consumption values are in accordance with other reports from the literature (Figure 3). Whereas BUP and COD loads do not exhibit any weekly pattern, TRA and METD are excreted less during weekend days with values of -7 and $-12.9 \%$, respectively (Figure 2). This trend was previously observed on other DTR such as KET and SUL, and could thus indicate the mobility of some consumers of these PAC out of the catchment. In addition, both TRA and METD can be used as ID substitutes. Weekday/weekend differences could thus potentially indicate a modification in medication during the weekend.

The calculation of HER consumption with HER as DTR is difficult due to the very low excretion rate of HER. Several authors therefore suggested using other opioids such as MOR and 6MAM as DTR of heroin (Baker et al., 2014; Gatidou et al., 2016; Terzic et al., 2010). However, MOR is mostly consumed as a therapeutic drug whereas the use of heroin is illicit. Although the excretion rate of 6MAM is low, which explains why this compound is barely detected, it presents the advantage of resulting exclusively from the metabolism of heroin (Kolmonen et al., 2010). In the present study, we calculated wastewater-based heroin consumption from both MOR and 6MAM (Table 3). The resulting heroin consumption was sixteen times higher based on MOR than on 6MAM loads. This could be explained, by the numerous origins of "legal" MOR (i.e. COD, ethylmorphine, pholcodine and MOR itself in Baker et al., 2014), that are far more consumed/excreted than the "illegal" MOR, generated by the consumption of HER.

However, a statistically significant correlation was noted between MOR and 6MAM, with a value of 0.3 (Table 4). Such a link between these two compounds needs to be confirmed but the statistical correlation remains lower than other associated medication, probably related to the multiple sources of these compounds. 
Heroin consumption based on MOR excretion values, which represent both therapeutic MOR and illicit heroin consumption, can thus lead to an overestimation of heroin consumption (Baker et al., 2014; van Nuijs et al., 2011). The consumption assessment of MOR based on MOR loads gave a

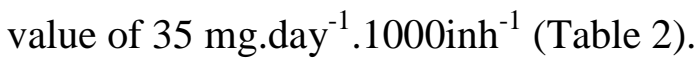

\begin{tabular}{|c|c|c|c|c|c|c|c|c|c|c|}
\hline \multirow[t]{2}{*}{ DTR } & \multirow{2}{*}{$\begin{array}{l}\text { Parent } \\
\text { Compound }\end{array}$} & \multirow{2}{*}{$\begin{array}{l}\% \% \\
\text { excreted } \\
\text { as DTR }\end{array}$} & \multirow{2}{*}{$\begin{array}{l}\text { Molar } \\
\text { Ratio }\end{array}$} & \multirow[t]{2}{*}{ Stability $^{\mathrm{b}}$} & \multirow{2}{*}{$\begin{array}{l}\text { Sorption to } \\
\text { SSP (\%) }\end{array}$} & \multirow{2}{*}{$\begin{array}{l}\text { Correction } \\
\text { Factor }\end{array}$} & \multirow{2}{*}{$\begin{array}{c}\text { Dose }^{\mathrm{c}} \\
(\mathrm{mg})\end{array}$} & \multirow{2}{*}{$\begin{array}{l}\text { Consumption } \\
\text { mg.day }{ }^{-1} \cdot 1000 \\
\text { inh }^{-1}\end{array}$} & \multicolumn{2}{|c|}{ doses.day $^{-1} .1000 \mathrm{inh}^{-1}$} \\
\hline & & & & & & & & & W & WE \\
\hline \multicolumn{11}{|c|}{ Cocaine and derivatives } \\
\hline $\mathrm{COC}$ & - & $7.5^{\mathrm{a}}$ & 1 & -7.7 & $1.4^{\mathrm{b}}$ & 13.52 & \multirow[b]{2}{*}{30} & 101 & 2.72 & 3.42 \\
\hline BZE & Cocaine & $45^{\mathrm{a}}$ & 1.05 & 5.5 & $0.4^{\mathrm{b}}$ & 2.34 & & 32 & 1.02 & 1.24 \\
\hline CET & Cocaine+ethanol & n.d. & 0.96 & -6.8 & $1.3^{\mathrm{b}}$ & - & - & n.d. & - & - \\
\hline \multicolumn{11}{|c|}{ Other illicit drugs } \\
\hline MDMA & - & $20.3^{\mathrm{b}}$ & 1 & 1.4 & $1.1^{\mathrm{b}}$ & 4.98 & 97 & 6 & 0.05 & 0.07 \\
\hline THC-COOH & Cannabis & $0.6^{\mathrm{b}}$ & 0.91 & n.d. & n.d. & 151.67 & 125 & 51,423 & 396 & 430 \\
\hline MOR & Heroin & $55^{\mathrm{b}}$ & 1.33 & 48.9 & $0.9^{\mathrm{b}}$ & 2.44 & 10 & 99 & 19.1 & 19.0 \\
\hline 6МAM & Heroin & $1.3^{\mathrm{a}}$ & 1.12 & -12.0 & n.d. & 86.15 & 10 & 14 & 1.34 & 1.18 \\
\hline
\end{tabular}

Table 3: Consumption assessment of illicit drugs with dose the average dose used, W weekdays and WE weekend days

References

${ }^{\text {a }}$ Gracia-Lor et al., (2016)

${ }^{\mathrm{b}}$ Baker et al., (2014)

${ }^{c}$ Krizman et al., (2016)

\section{Illicit drugs}

With a defined dose of $10 \mathrm{mg}$ (Table 3), the mean daily number of HER doses consumed in the catchment was 1.27 doses.day ${ }^{-1} .1000 \mathrm{inh}^{-1}$, corresponding to the use of HER by $0.13 \%$ of the population based on 6MAM loads (Table 3).

As for HER (based on MOR or 6MAM loads), no weekly trend was found for THC-COOH consumption. With a wastewater-based consumption of $51,423 \mathrm{mg}^{-\mathrm{day}^{-1}} .1000 \mathrm{inh}^{-1}$ and a defined dose of $125 \mathrm{mg}$, the mean daily amount of cannabis doses is about 411 doses.day $^{-1} .1000 \mathrm{inh}^{-1}$. Considering a population of 70,000 in the catchment, the number of doses is high with a consumer percentage of $41 \%$, based on one dose per day and per consumer (Table 3). This value should probably be corrected by the number of consumers of more than one dose per day. However, cannabis is the most widely consumed ID in France and according to the EMCDDA, 
the prevalence of consumption was about 40.9\% in 2014 (EMCDDA, 2016a). Our results are therefore in accordance with the general finding that France is the highest consumer of cannabis in Europe (Nefau et al., 2013; Thomas et al., 2012).

COC and MDMA are the last two IDs examined in this study and are both considered as recreational drugs (Gatidou et al., 2016; Nefau et al., 2013). For these two compounds, a significant variation was found between weekdays and weekend days. Whereas only MDMA was determined and used to estimate ecstasy consumption, three DTR were used to estimate COC consumption (i.e. COC, BZE and CET). COC and its principal degradation product BZE present a similar pattern with a $20 \%$ load increase during weekends (Figure 2). Moreover, the statistical correlation between COC and BZE is significant (Table 4). CET is a DTR resulting from the use of both COC and ethanol. It exhibits the highest variation between weekdays and weekend days among the selected DTR (i.e. $+50.9 \%$ ). Cocaine consumption should therefore be calculated from BZE or COC loads. BZE is generally preferred for the calculation of COC consumption due to its higher concentration in sewage and its better stability (Gracia-Lor et al., 2016; Zuccato et al., 2008). The defined dose of COC is $30 \mathrm{mg}$ given a mean daily number of consumed doses of 1.02 and 1.24 doses.day ${ }^{-1} .1000 \mathrm{inh}^{-1}$ on weekdays and weekend days respectively based on BZE loads (Table 4).

The same calculation can be achieved for MDMA for which the defined dose is $97 \mathrm{mg}$, resulting in a mean daily number of consumed doses of 3.2 and 5.1 doses.day $^{-1}$ on weekdays and weekend days, corresponding to 0.05 and 0.07 doses.day ${ }^{-1} .1000 \mathrm{inh}^{-1}$ respectively (Table 3). This number of daily doses is low but consistent with other reports in France (Nefau et al., 2013).

At a national scale, these wastewater-based consumptions can be compared with other French cities that participate to the EMCDDA; Paris and Bordeaux (EMCDDA, 2016b). For MDMA, the mean consumption values in 2016 are 0.14 and 0.17 doses.day $^{-1} .1000$ inh $^{-1}$ for Bordeaux and 
Paris, respectively. In this study, the mean consumption value is 0.06 doses.day $^{-1} .1000 \mathrm{inh}^{-1}$, i.e. significantly lower than in bigger cities. The same trend can be noticed on COC consumptions (based on BZE loads) with mean consumption values of $1.12,8.20$ and 5.52 mg.day $^{-1} .1000 \mathrm{inh}^{-1}$ for this study, Bordeaux and Paris respectively. As a result, the consumption of COC and MDMA in the investigated city, smaller than Bordeaux and Paris, is significantly lower indicating that national scale variations can be important.

From a statistical point of view, BZE loads are significantly correlated with MDMA and COC loads, probably due to the weekday/weekend day difference that is in the same order of magnitude for these three compounds. Conversely, CET and THC-COOH loads are not correlated with other IDs (Table 4). 


\begin{tabular}{|c|c|c|c|c|c|c|c|c|c|c|c|c|c|c|c|c|c|c|c|c|c|c|}
\hline \multirow[b]{2}{*}{ ATE } & \multicolumn{2}{|l|}{$\mathrm{ACM}$} & & & & & & & & & & & & & & & & & & & & \\
\hline & $0.34^{* *}$ & ATE & & & & & & & & & & & & & & & & & & & & \\
\hline BUP & 0.09 & $0.26^{*}$ & BUP & & & & & & & & & & & & & & & & & & & \\
\hline BZB & $0.46^{* * *}$ & $0.31^{* *}$ & 0.16 & BZB & & & & & & & & & & & & & & & & & & \\
\hline BZE & 0.06 & 0.02 & -0.01 & 0.05 & BZE & & & & & & & & & & & & & & & & & \\
\hline CBZ & 0.10 & 0.05 & 0.10 & -0.00 & 0.04 & $\mathrm{CBZ}$ & & & & & & & & & & & & & & & & \\
\hline CET & -0.10 & 0.14 & 0.02 & -0.08 & 0.16 & 0.07 & CET & & & & & & & & & & & & & & & \\
\hline $\mathrm{COC}$ & 0.05 & -0.15 & 0.07 & -0.07 & $0.36^{* * * *}$ & -0.01 & 0.03 & $\overline{\mathrm{COC}}$ & & & & & & & & & & & & & & \\
\hline COD & $0.25^{*}$ & 0.13 & $0.27^{*}$ & $0.35^{* *}$ & 0.14 & $0.39^{* * *}$ & -0.11 & 0.02 & COD & & & & & & & & & & & & & \\
\hline DCF & $0.35^{* *}$ & $0.34^{* *}$ & 0.20 & $0.35^{* *}$ & 0.11 & 0.03 & 0.08 & 0.02 & 0.21 & DCF & & & & & & & & & & & & \\
\hline IBP & $0.57^{* * *}$ & $0.23^{*}$ & 0.04 & $0.42^{* * *}$ & -0.00 & 0.03 & -0.12 & -0.10 & $0.32^{* *}$ & $0.52^{* * * *}$ & IBP & & & & & & & & & & & \\
\hline KET & $0.50^{* * * *}$ & $0.25^{*}$ & 0.20 & $0.47^{* * * *}$ & 0.01 & 0.02 & -0.13 & -0.13 & $0.55^{* * *}$ & $0.42^{* * *}$ & $0.65^{* * *}$ & KET & & & & & & & & & & \\
\hline MDMA & 0.08 & -0.10 & -0.07 & -0.09 & $0.37^{* * * *}$ & 0.13 & 0.14 & 0.06 & -0.01 & 0.20 & 0.18 & 0.15 & MDMA & & & & & & & & & \\
\hline MET & $0.41^{* * *}$ & 0.02 & -0.16 & $0.33^{* *}$ & -0.04 & -0.04 & -0.13 & -0.09 & $0.34^{* *}$ & $0.26^{*}$ & $0.54^{* * *}$ & $0.63^{* * *}$ & 0.21 & MET & & & & & & & & \\
\hline METD & $0.34^{* *}$ & $0.42^{* * *}$ & $0.30^{* *}$ & $0.40^{* * *}$ & -0.09 & 0.00 & $-0.27^{*}$ & -0.15 & $0.37^{* * *}$ & 0.20 & $0.39^{* * *}$ & $0.39^{* * *}$ & $-0.23^{*}$ & 0.04 & $\overline{\text { METD }}$ & & & & & & & \\
\hline MOR & $0.26^{*}$ & $0.24^{*}$ & $0.22^{*}$ & $0.43^{* * * *}$ & $0.43^{* * * *}$ & 0.05 & -0.07 & -0.10 & $0.48^{* * *}$ & $0.37^{* * *}$ & $0.30^{* *}$ & $0.46^{* * * *}$ & 0.13 & $0.34^{* *}$ & $0.33^{* *}$ & MOR & & & & & & \\
\hline OXA & 0.10 & $0.27^{*}$ & $0.34^{* *}$ & $0.32^{* *}$ & 0.11 & -0.11 & -0.05 & -0.11 & $0.43^{* * *}$ & $0.41^{* * *}$ & $0.45^{* * *}$ & $0.57^{* * * *}$ & 0.04 & $0.40^{* * * *}$ & $0.37^{* * *}$ & $0.57^{* * *}$ & OXA & & & & & \\
\hline SCA & $0.55^{* * *}$ & 0.12 & -0.01 & $0.43^{* * *}$ & $0.30^{* *}$ & $0.33^{* *}$ & -0.10 & -0.02 & $0.61^{* * *}$ & 0.14 & $0.42^{* * * *}$ & $0.50^{* * * *}$ & 0.07 & $0.37^{* * * *}$ & 0.22 & $0.49^{* * * *}$ & $0.22^{*}$ & SCA & & & & \\
\hline SUL & $0.24^{*}$ & $0.22^{*}$ & 0.19 & 0.19 & 0.03 & -0.01 & $-0.25^{*}$ & 0.21 & $0.24^{*}$ & -0.07 & 0.16 & 0.19 & -0.17 & 0.16 & $0.32^{* *}$ & $0.29^{* *}$ & 0.14 & 0.21 & SUL & & & \\
\hline THC & $0.41^{* * *}$ & $0.45^{* * *}$ & $0.59^{* * *}$ & 0.17 & 0.06 & 0.09 & 0.02 & -0.08 & 0.09 & $0.43^{* * *}$ & $0.36^{* * *}$ & $0.41^{* * *}$ & 0.21 & -0.03 & $0.35^{* *}$ & $0.22^{*}$ & $0.32^{* *}$ & 0.17 & 0.07 & THC & & \\
\hline TMP & $0.36^{* * *}$ & $0.34^{* *}$ & 0.20 & 0.07 & 0.00 & 0.00 & $-0.23^{*}$ & 0.00 & 0.09 & -0.04 & 0.21 & $0.31^{* *}$ & -0.05 & 0.12 & $0.33^{* *}$ & $0.24^{*}$ & 0.15 & 0.15 & $0.65^{* * *}$ & $0.40^{* * *}$ & TMP & \\
\hline TRA & 0.17 & 0.12 & -0.04 & 0.16 & $-0.26^{*}$ & 0.04 & -0.17 & -0.01 & $0.30^{* *}$ & -0.02 & 0.18 & $0.23^{*}$ & -0.12 & 0.20 & $0.26^{*}$ & -0.09 & 0.02 & 0.11 & 0.17 & -0.01 & 0.12 & TRA \\
\hline $6 \mathrm{MAM}$ & -0.06 & 0.09 & $0.25^{*}$ & 0.02 & $0.22^{*}$ & -0.05 & -0.02 & 0.07 & -0.02 & -0.01 & -0.00 & -0.01 & 0.02 & -0.07 & 0.00 & $0.30^{* * *}$ & 0.17 & -0.05 & 0.06 & 0.21 & $0.23^{*}$ & -0.20 \\
\hline
\end{tabular}

Table 4: Correlation coefficients describe the relationship between loads of each detected DTR. ${ }^{*},{ }^{* *}$ and ${ }^{* * * *}$ correspond to $p$-values $<0.05,0.01$ and 0.001 respectively 


\subsection{Statistical variation assessment between DTRs from various classes}

Beyond their belonging to various therapeutic classes, the load variation of each DTR in influents is mostly controlled by the consumption pattern of the parent compound. The distinction between PAC and ID often used in the literature to distinguish a potential temporal trend is thus difficult to assume because several IDs are regularly consumed without either a weekly or a monthly pattern. Except for COC, MDMA and DCF, none of the compounds exhibited a significantly higher excretion during the weekend days. No firm conclusion can be reached for DCF. Conversely, this weekly pattern was regularly demonstrated in the literature for COC and MDMA (e.g. Gatidou et al., 2016; Vuori et al., 2014). Consequently, COC and MDMA are not significantly correlated with other compounds, except BZE. CET exhibited a stronger weekly pattern (i.e. $+50.9 \%)$. CET was correlated with no other compound but rather significantly anticorrelated with SUL, TMP and METD (Table 4), three compounds consumed significantly less during weekend days (Figure 2). Thus, the correlation coefficients represent well the links between compounds that present similar or opposite weekly patterns.

In Table 4, several significant correlations can be noticed on widely consumed drugs such as ACM, SCA and other anti-inflammatory drugs. THC-COOH is also significantly correlated with this pool, indicating that from a wastewater-based evaluation, cannabis should be considered as a regularly consumed ID, as should the ID substitutes BUP and METD.

At the scale of this study, most of the selected compounds should be considered as regularly consumed products whereas some of them, such as analgesics, are intermittently consumed by an individual consumer at a daily scale. As the study was limited to a single season, additional seasonal effects can be expected on larger time scales especially for antibiotics (Golovko et al., 2014; Sui et al., 2011). 


\section{Conclusion}

The load of 25 human-excreted DTRs in wastewater was analyzed during 85 consecutive days. This large database enabled us to investigate the temporal pattern of loads for each DTR. Although the variation between weekdays and weekend days was already noticed for recreational IDs such as COC and MDMA, an opposite trend was observed for the first time for some PACs such as MET or METD for which the loads are significantly lower during weekend days. Beyond this variation, we assume that load variations of PACs, especially those used to treat chronic disease (e.g. MET) are controlled by the weekly mobility of people in the catchment.

The weekly pattern observed for several IDs varied considerably, with maximum values for MDMA and CET (i.e. + 35.9 and $50.9 \%$ during weekend days). Although CET is considered as a degradation product of $\mathrm{COC}$, no significant correlation was found between CET and COC, probably due to the fact CET metabolization requires taking into account both $\mathrm{COC}$ and ethanol.

Based on their correlation coefficients, DTRs were grouped independently of their use. For example, even though $\mathrm{THC}-\mathrm{COOH}$ is derived from an ID (i.e. cannabis), its load variations during the study are closer to those of widely consumed medication, such as ACM or DCF, than to those of other IDs.

Moreover, the daily over an extended period tracking allowed a better understanding of the quantitative relationship between some parent compounds and their DTR. For example, in the opioid group, although 6MAM and MOR are statistically significantly correlated, 6MAM is a better guide to calculate HER consumption due to its unique origin.

Finally, wastewater-based consumptions of IDs and PACs determined in this study are in general agreement with the literature. Some site-dependent features were revealed, such as the highest 
consumption value ever found for cannabis (i.e. 51.4 mg.day ${ }^{-1} \cdot \mathrm{inh}^{-1}$ ). Similarly, wastewater-based consumption of IBP is significantly lower than in other studies.

\section{Acknowledgements}

The authors gratefully acknowledge Cedric Morio and Olivier Cantaloube for the sampling authorization and Pascale Moret for both the analysis of physico-chemical parameters of wastewater influents and the sample delivery. Sara Karolak is thanked for providing illicit drug standards. This work is part of the "Golden Spike" project supported by the CNRS/INSU EC2CO-Biohefect program. Labex VOLTAIRE (NR-10-LABX-100-01) is acknowledged for providing a grant to M.R. 


\section{References}

Bahlmann, A., Brack, W., Schneider, R.J., Krauss, M., 2014. Carbamazepine and its metabolites in wastewater: Analytical pitfalls and occurrence in Germany and Portugal. Water Res. 57, 104-114. doi:10.1016/j.watres.2014.03.022

Baker, D.R., Barron, L., Kasprzyk-Hordern, B., 2014. Illicit and pharmaceutical drug consumption estimated via wastewater analysis. Part A: Chemical analysis and drug use estimates. Sci. Total Environ. 487, 629-641. doi:10.1016/j.scitotenv.2013.11.107

Baz-Lomba, J.A., Salvatore, S., Gracia-Lor, E., Bade, R., Castiglioni, S., Castrignanò, E., Causanilles, A., Hernandez, F., Kasprzyk-Hordern, B., Kinyua, J., McCall, A.-K., van Nuijs, A., Ort, C., Plósz, B.G., Ramin, P., Reid, M., Rousis, N.I., Ryu, Y., de Voogt, P., Bramness, J., Thomas, K., 2016. Comparison of pharmaceutical, illicit drug, alcohol, nicotine and caffeine levels in wastewater with sale, seizure and consumption data for 8 European cities. BMC Public Health 16, 1035. doi:10.1186/s12889-016-3686-5

Behera, S.K., Kim, H.W., Oh, J.-E., Park, H.-S., 2011. Occurrence and removal of antibiotics, hormones and several other pharmaceuticals in wastewater treatment plants of the largest industrial city of Korea. Sci. Total Environ. 409, 4351-4360.

doi:10.1016/j.scitotenv.2011.07.015

Besse, J.-P., Kausch-Barreto, C., Garric, J., 2008. Exposure Assessment of Pharmaceuticals and Their Metabolites in the Aquatic Environment: Application to the French Situation and Preliminary Prioritization. Hum. Ecol. Risk Assess. Int. J. 14, 665-695. doi:10.1080/10807030802235078

Bijlsma, L., Emke, E., Hernández, F., de Voogt, P., 2012. Investigation of drugs of abuse and relevant metabolites in Dutch sewage water by liquid chromatography coupled to high resolution mass spectrometry. Chemosphere 89, 1399-1406. doi:10.1016/j.chemosphere.2012.05.110

Brodin, T., Piovano, S., Fick, J., Klaminder, J., Heynen, M., Jonsson, M., 2014. Ecological effects of pharmaceuticals in aquatic systems - impacts through behavioural alterations. Philos. Trans. R. Soc. Lond. B Biol. Sci. 369, 20130580. doi:10.1098/rstb.2013.0580

Bueno, M.J.M., Gomez, M.J., Herrera, S., Hernando, M.D., Agüera, A., Fernández-Alba, A.R., 2012. Occurrence and persistence of organic emerging contaminants and priority pollutants in five sewage treatment plants of Spain: Two years pilot survey monitoring. Environ. Pollut. 164, 267-273. doi:10.1016/j.envpol.2012.01.038

Carballa, M., Omil, F., Lema, J.M., 2008. Comparison of predicted and measured concentrations of selected pharmaceuticals, fragrances and hormones in Spanish sewage. Chemosphere 72, 1118-1123. doi:10.1016/j.chemosphere.2008.04.034

Castiglioni, S., Bagnati, R., Fanelli, R., Pomati, F., Calamari, D., Zuccato, E., 2006a. Removal of Pharmaceuticals in Sewage Treatment Plants in Italy. Environ. Sci. Technol. 40, 357-363. doi:10.1021/es050991m

Castiglioni, S., Zuccato, E., Crisci, E., Chiabrando, C., Fanelli, R., Bagnati, R., $2006 \mathrm{~b}$. Identification and Measurement of Illicit Drugs and Their Metabolites in Urban Wastewater by Liquid Chromatography-Tandem Mass Spectrometry. Anal. Chem. 78, 8421-8429. doi:10.1021/ac061095b

Celle-Jeanton, H., Schemberg, D., Mohammed, N., Huneau, F., Bertrand, G., Lavastre, V., Le Coustumer, P., 2014. Evaluation of pharmaceuticals in surface water: Reliability of PECs compared to MECs. Environ. Int. 73, 10-21. doi:10.1016/j.envint.2014.06.015 
Chiffre, A., Degiorgi, F., Buleté, A., Spinner, L., Badot, P.-M., 2016. Occurrence of pharmaceuticals in WWTP effluents and their impact in a karstic rural catchment of Eastern France. Environ. Sci. Pollut. Res. 1-15. doi:10.1007/s11356-016-7751-5

Collado, N., Rodriguez-Mozaz, S., Gros, M., Rubirola, A., Barceló, D., Comas, J., RodriguezRoda, I., Buttiglieri, G., 2014. Pharmaceuticals occurrence in a WWTP with significant industrial contribution and its input into the river system. Environ. Pollut. 185, 202-212. doi:10.1016/j.envpol.2013.10.040

Coutu, S., Wyrsch, V., Wynn, H.K., Rossi, L., Barry, D.A., 2013. Temporal dynamics of antibiotics in wastewater treatment plant influent. Sci. Total Environ. 458-460, 20-26. doi:10.1016/j.scitotenv.2013.04.017

Dan, A., Yang, Y., Yu-nv, D., Chun-xing, C., Su-yu, W., Ran, T., 2013. Removal and factors influencing removal of sulfonamides and trimethoprim from domestic sewage in constructed wetlands. Bioresour. Technol. 146, 363-370. doi:10.1016/j.biortech.2013.07.050

De Jongh, C.M., Kooij, P.J.F., de Voogt, P., ter Laak, T.L., 2012. Screening and human health risk assessment of pharmaceuticals and their transformation products in Dutch surface waters and drinking water. Sci. Total Environ. 427-428, 70-77. doi:10.1016/j.scitotenv.2012.04.010

Deblonde, T., Cossu-Leguille, C., Hartemann, P., 2011. Emerging pollutants in wastewater: A review of the literature. Int. J. Hyg. Environ. Health, The second European PhD students workshop: Water and health ? Cannes 2010 214, 442-448. doi:10.1016/j.ijheh.2011.08.002

EMCDDA, 2016a. European Drug Report 2016: Trends and Developments. URL http://www.emcdda.europa.eu/publications/edr/trends-developments/2016 (accessed 4.5.17).

EMCDDA, 2016b. Perspectives on drugs; Wastewater analysis and drugs: multi-city study. URL http://www.emcdda.europa.eu/topics/pods/waste-water-analysis\#panel2 (accessed 4.5.17).

Fatta-Kassinos, D., Meric, S., Nikolaou, A., 2011. Pharmaceutical residues in environmental waters and wastewater: current state of knowledge and future research. Anal. Bioanal. Chem. 399, 251-275. doi:10.1007/s00216-010-4300-9

Gatidou, G., Kinyua, J., van Nuijs, A.L.N., Gracia-Lor, E., Castiglioni, S., Covaci, A., Stasinakis, A.S., 2016. Drugs of abuse and alcohol consumption among different groups of population on the Greek Island of Lesvos through sewage-based epidemiology. Sci. Total Environ. 563-564, 633-640. doi:10.1016/j.scitotenv.2016.04.130

Gerrity, D., Trenholm, R.A., Snyder, S.A., 2011. Temporal variability of pharmaceuticals and illicit drugs in wastewater and the effects of a major sporting event. Water Res. 45, 53995411. doi:10.1016/j.watres.2011.07.020

Golovko, O., Kumar, V., Fedorova, G., Randak, T., Grabic, R., 2014. Seasonal changes in antibiotics, antidepressants/psychiatric drugs, antihistamines and lipid regulators in a wastewater treatment plant. Chemosphere 111, 418-426. doi:10.1016/j.chemosphere.2014.03.132

Gracia-Lor, E., Sancho, J.V., Serrano, R., Hernández, F., 2012. Occurrence and removal of pharmaceuticals in wastewater treatment plants at the Spanish Mediterranean area of Valencia. Chemosphere 87, 453-462. doi:10.1016/j.chemosphere.2011.12.025

Gracia-Lor, E., Zuccato, E., Castiglioni, S., 2016. Refining correction factors for back-calculation of illicit drug use. Sci. Total Environ. 573, 1648-1659.

doi:10.1016/j.scitotenv.2016.09.179 
Gurke, R., Rößler, M., Marx, C., Diamond, S., Schubert, S., Oertel, R., Fauler, J., 2015. Occurrence and removal of frequently prescribed pharmaceuticals and corresponding metabolites in wastewater of a sewage treatment plant. Sci. Total Environ. 532, 762-770. doi:10.1016/j.scitotenv.2015.06.067

Hall, W., Prichard, J., Kirkbride, P., Bruno, R., Thai, P.K., Gartner, C., Lai, F.Y., Ort, C., Mueller, J.F., 2012. An analysis of ethical issues in using wastewater analysis to monitor illicit drug use. Addiction 107, 1767-1773. doi:10.1111/j.1360-0443.2012.03887.x

Hirsch, R., Ternes, T., Haberer, K., Kratz, K.-L., 1999. Occurrence of antibiotics in the aquatic environment. Sci. Total Environ. 225, 109-118. doi:10.1016/S0048-9697(98)00337-4

Hörsing, M., Ledin, A., Grabic, R., Fick, J., Tysklind, M., Jansen, J. la C., Andersen, H.R., 2011. Determination of sorption of seventy-five pharmaceuticals in sewage sludge. Water Res. 45, 4470-4482. doi:10.1016/j.watres.2011.05.033

Hummel, D., Löffler, D., Fink, G., Ternes, T.A., 2006. Simultaneous Determination of Psychoactive Drugs and Their Metabolites in Aqueous Matrices by Liquid Chromatography Mass Spectrometry. Environ. Sci. Technol. 40, 7321-7328. doi:10.1021/es061740w

Jelic, A., Gros, M., Ginebreda, A., Cespedes-Sánchez, R., Ventura, F., Petrovic, M., Barcelo, D., 2011. Occurrence, partition and removal of pharmaceuticals in sewage water and sludge during wastewater treatment. Water Res. 45, 1165-1176. doi:10.1016/j.watres.2010.11.010

Kasprzyk-Hordern, B., Dinsdale, R.M., Guwy, A.J., 2009. Illicit drugs and pharmaceuticals in the environment - Forensic applications of environmental data. Part 1: Estimation of the usage of drugs in local communities. Environ. Pollut. 157, 1773-1777. doi:10.1016/j.envpol.2009.03.017

Kasprzyk-Hordern, B., Dinsdale, R.M., Guwy, A.J., 2008. The occurrence of pharmaceuticals, personal care products, endocrine disruptors and illicit drugs in surface water in South Wales, UK. Water Res. 42, 3498-3518. doi:10.1016/j.watres.2008.04.026

Klaminder, J., Brodin, T., Sundelin, A., Anderson, N.J., Fahlman, J., Jonsson, M., Fick, J., 2015. Long-term persistence of an anxiolytic drug (oxazepam) in a large freshwater lake. Environ. Sci. Technol. 49, 10406-10412. doi:10.1021/acs.est.5b01968

Kolmonen, M., Leinonen, A., Kuuranne, T., Pelander, A., Ojanperä, I., 2010. Hydrophilic interaction liquid chromatography and accurate mass measurement for quantification and confirmation of morphine, codeine and their glucuronide conjugates in human urine. J. Chromatogr. B 878, 2959-2966. doi:10.1016/j.jchromb.2010.08.047

Kosma, C.I., Lambropoulou, D.A., Albanis, T.A., 2014. Investigation of PPCPs in wastewater treatment plants in Greece: Occurrence, removal and environmental risk assessment. Sci. Total Environ. 466-467, 421-438. doi:10.1016/j.scitotenv.2013.07.044

Krizman, I., Senta, I., Ahel, M., Terzic, S., 2016. Wastewater-based assessment of regional and temporal consumption patterns of illicit drugs and therapeutic opioids in Croatia. Sci. Total Environ. 566-567, 454-462. doi:10.1016/j.scitotenv.2016.05.075

Lai, F.Y., Anuj, S., Bruno, R., Carter, S., Gartner, C., Hall, W., Kirkbride, K.P., Mueller, J.F., Prichard, J., Thai, P.K., Ort, C., 2015. Systematic and Day-to-Day Effects of ChemicalDerived Population Estimates on Wastewater-Based Drug Epidemiology. Env. Sci. Technol. 49, 999-1008. doi:10/1021/es503474d

Lê, S., Josse, J., Husson, F., others, 2008. FactoMineR: an R package for multivariate analysis. J. Stat. Softw. 25, 1-18. doi:10.18637/jss.v025.i01 
Lienert, J., Güdel, K., Escher, B.I., 2007. Screening Method for Ecotoxicological Hazard Assessment of 42 Pharmaceuticals Considering Human Metabolism and Excretory Routes. Environ. Sci. Technol. 41, 4471-4478. doi:10.1021/es0627693

Lindberg, R.H., Östman, M., Olofsson, U., Grabic, R., Fick, J., 2014. Occurrence and behaviour of 105 active pharmaceutical ingredients in sewage waters of a municipal sewer collection system. Water Res. 58, 221-229. doi:10.1016/j.watres.2014.03.076

Loos, R., Gawlik, B.M., Locoro, G., Rimaviciute, E., Contini, S., Bidoglio, G., 2009. EU-wide survey of polar organic persistent pollutants in European river waters. Environ. Pollut. 157, 561-568. doi:10.1016/j.envpol.2008.09.020

Lopez, B., Ollivier, P., Togola, A., Baran, N., Ghestem, J.-P., 2015. Screening of French groundwater for regulated and emerging contaminants. Sci. Total Environ. 518-519, 562573. doi:10.1016/j.scitotenv.2015.01.110

Mackul’ak, T., Birošová, L., Bodík, I., Grabic, R., Takáčová, A., Smolinská, M., Hanusová, A., Híveš, J., Gál, M., 2016. Zerovalent iron and iron(VI): Effective means for the removal of psychoactive pharmaceuticals and illicit drugs from wastewaters. Sci. Total Environ. 539, 420-426. doi:10.1016/j.scitotenv.2015.08.138

Mailler, R., Gasperi, J., Coquet, Y., Deshayes, S., Zedek, S., Cren-Olivé, C., Cartiser, N., Eudes, V., Bressy, A., Caupos, E., Moilleron, R., Chebbo, G., Rocher, V., 2015. Study of a large scale powdered activated carbon pilot: Removals of a wide range of emerging and priority micropollutants from wastewater treatment plant effluents. Water Res. 72, 315-330. doi:10.1016/j.watres.2014.10.047

Mompelat, S., Le Bot, B., Thomas, O., 2009. Occurrence and fate of pharmaceutical products and by-products, from resource to drinking water. Environ. Int. 35, 803-814. doi:10.1016/j.envint.2008.10.008

Nefau, T., Karolak, S., Castillo, L., Boireau, V., Levi, Y., 2013. Presence of illicit drugs and metabolites in influents and effluents of 25 sewage water treatment plants and map of drug consumption in France. Sci. Total Environ. 461-462, 712-722. doi:10.1016/j.scitotenv.2013.05.038

Ort, C., van Nuijs, A.L.N., Berset, J.-D., Bijlsma, L., Castiglioni, S., Covaci, A., de Voogt, P., Emke, E., Fatta-Kassinos, D., Griffiths, P., Hernández, F., González-Mariño, I., Grabic, R., Kasprzyk-Hordern, B., Mastroianni, N., Meierjohann, A., Nefau, T., Östman, M., Pico, Y., Racamonde, I., Reid, M., Slobodnik, J., Terzic, S., Thomaidis, N., Thomas, K.V., 2014. Spatial differences and temporal changes in illicit drug use in Europe quantified by wastewater analysis. Addiction 109, 1338-1352. doi:10.1111/add.12570

Papageorgiou, M., Kosma, C., Lambropoulou, D., 2016. Seasonal occurrence, removal, mass loading and environmental risk assessment of 55 pharmaceuticals and personal care products in a municipal wastewater treatment plant in Central Greece. Sci. Total Environ. 543, Part A, 547-569. doi:10.1016/j.scitotenv.2015.11.047

Pereira, A.M.P.T., Silva, L.J.G., Lino, C.M., Meisel, L.M., Pena, A., 2016. Assessing environmental risk of pharmaceuticals in Portugal: An approach for the selection of the Portuguese monitoring stations in line with Directive 2013/39/EU. Chemosphere 144, 2507-2515. doi:10.1016/j.chemosphere.2015.10.100

Petrovic, M., Alda, M.J.L. de, Diaz-Cruz, S., Postigo, C., Radjenovic, J., Gros, M., Barcelo, D., 2009. Fate and removal of pharmaceuticals and illicit drugs in conventional and membrane bioreactor wastewater treatment plants and by riverbank filtration. Philos. Trans. R. Soc. Lond. Math. Phys. Eng. Sci. 367, 3979-4003. doi:10.1098/rsta.2009.0105 
Plósz, B.G., Leknes, H., Liltved, H., Thomas, K.V., 2010. Diurnal variations in the occurrence and the fate of hormones and antibiotics in activated sludge wastewater treatment in Oslo, Norway. Sci. Total Environ. 408, 1915-1924. doi:10.1016/j.scitotenv.2010.01.042

Postigo, C., de Alda, M.L., Barceló, D., 2011. Evaluation of drugs of abuse use and trends in a prison through wastewater analysis. Environ. Int. 37, 49-55.

doi:10.1016/j.envint.2010.06.012

Postigo, C., López de Alda, M.J., Barceló, D., 2010. Drugs of abuse and their metabolites in the Ebro River basin: Occurrence in sewage and surface water, sewage treatment plants removal efficiency, and collective drug usage estimation. Environ. Int. 36, 75-84. doi:10.1016/j.envint.2009.10.004

Prichard, J., Hall, W., de Voogt, P., Zuccato, E., 2014. Sewage epidemiology and illicit drug research: The development of ethical research guidelines. Sci. Total Environ. 472, 550555. doi:10.1016/j.scitotenv.2013.11.039

Rattier, M., Reungoat, J., Keller, J., Gernjak, W., 2014. Removal of micropollutants during tertiary wastewater treatment by biofiltration: Role of nitrifiers and removal mechanisms. Water Res. 54, 89-99. doi:10.1016/j.watres.2014.01.030

Rosal, R., Rodríguez, A., Perdigón-Melón, J.A., Petre, A., García-Calvo, E., Gómez, M.J., Agüera, A., Fernández-Alba, A.R., 2010. Occurrence of emerging pollutants in urban wastewater and their removal through biological treatment followed by ozonation. Water Res., Emerging Contaminants in water: Occurrence, fate, removal and assessment in the water cycle (from wastewater to drinking water) 44, 578-588. doi:10.1016/j.watres.2009.07.004

Subedi, B., Kannan, K., 2014. Mass Loading and Removal of Select Illicit Drugs in Two Wastewater Treatment Plants in New York State and Estimation of Illicit Drug Usage in Communities through Wastewater Analysis. Environ. Sci. Technol. 48, 6661-6670. doi:10.1021/es501709a

Sui, Q., Huang, J., Deng, S., Chen, W., Yu, G., 2011. Seasonal Variation in the Occurrence and Removal of Pharmaceuticals and Personal Care Products in Different Biological Wastewater Treatment Processes. Environ. Sci. Technol. 45, 3341-3348. doi:10.1021/es200248d

Terzic, S., Senta, I., Ahel, M., 2010. Illicit drugs in wastewater of the city of Zagreb (Croatia) Estimation of drug abuse in a transition country. Environ. Pollut. 158, 2686-2693. doi:10.1016/j.envpol.2010.04.020

Thiebault, T., Boussafir, M., Guégan, R., Le Milbeau, C., Le Forestier, L., 2016. Clayey-sand filter for the removal of pharmaceuticals from wastewater effluent: percolation experiments. Environ. Sci. Water Res. Technol. 2, 529-538. doi:10.1039/C6EW00034G

Thiebault, T., Boussafir, M., Le Milbeau, C., 2017. Occurrence and removal efficiency of pharmaceuticals in an urban wastewater treatment plant: mass balance and consumption assessment. Submitt. J. Environ. Chem. Eng.

Thomas, K.V., Bijlsma, L., Castiglioni, S., Covaci, A., Emke, E., Grabic, R., Hernández, F., Karolak, S., Kasprzyk-Hordern, B., Lindberg, R.H., Lopez de Alda, M., Meierjohann, A., Ort, C., Pico, Y., Quintana, J.B., Reid, M., Rieckermann, J., Terzic, S., van Nuijs, A.L.N., de Voogt, P., 2012. Comparing illicit drug use in 19 European cities through sewage analysis. Sci. Total Environ. 432, 432-439. doi:10.1016/j.scitotenv.2012.06.069

van Nuijs, A.L.N., Mougel, J.-F., Tarcomnicu, I., Bervoets, L., Blust, R., Jorens, P.G., Neels, H., Covaci, A., 2011. Sewage epidemiology - A real-time approach to estimate the 
consumption of illicit drugs in Brussels, Belgium. Environ. Int. 37, 612-621. doi:10.1016/j.envint.2010.12.006

Vergeynst, L., Haeck, A., De Wispelaere, P., Van Langenhove, H., Demeestere, K., 2015. Multiresidue analysis of pharmaceuticals in wastewater by liquid chromatography-magnetic sector mass spectrometry: Method quality assessment and application in a Belgian case study. Emerg. Pollut. 119, Supplement, S2-S8. doi:10.1016/j.chemosphere.2014.03.069

Verlicchi, P., Galletti, A., Petrovic, M., Barceló, D., Al Aukidy, M., Zambello, E., 2013. Removal of selected pharmaceuticals from domestic wastewater in an activated sludge system followed by a horizontal subsurface flow bed - Analysis of their respective contributions. Sci. Total Environ. 454-455, 411-425. doi:10.1016/j.scitotenv.2013.03.044

Verlicchi, P., Al Aukidy, M., Zambello, E., 2012. Occurrence of pharmaceutical compounds in urban wastewater: Removal, mass load and environmental risk after a secondary treatment-A review. Sci. Total Environ. 429, 123-155. doi:10.1016/j.scitotenv.2012.04.028

Vuori, E., Happonen, M., Gergov, M., Nenonen, T., Järvinen, A., Ketola, R.A., Vahala, R., 2014. Wastewater analysis reveals regional variability in exposure to abused drugs and opioids in Finland. Sci. Total Environ. 487, 688-695.

Wick, A., Fink, G., Joss, A., Siegrist, H., Ternes, T.A., 2009. Fate of beta blockers and psychoactive drugs in conventional wastewater treatment. Water Res. 43, 1060-1074. doi:10.1016/j.watres.2008.11.031

WHO Collaborating Center for Drug Statistics Methodology. ATC/DDD index. Available online at: https://www.whocc.no/atc_ddd_index/2016, [accessed on April 7, 2017]

Yan, Q., Gao, X., Huang, L., Gan, X.-M., Zhang, Y.-X., Chen, Y.-P., Peng, X.-Y., Guo, J.-S., 2014. Occurrence and fate of pharmaceutically active compounds in the largest municipal wastewater treatment plant in Southwest China: Mass balance analysis and consumption back-calculated model. Chemosphere 99, 160-170.

doi:10.1016/j.chemosphere.2013.10.062

Zuccato, E., Chiabrando, C., Castiglioni, S., Bagnati, R., Fanelli, R., 2008. Estimating Community Drug Abuse by Wastewater Analysis. Environ. Health Perspect. 116, 10271032. doi:10.1289/ehp.11022 